\title{
Direct electrochemical hydrogenation of toluene at Pt electrodes in a microemulsion electrolyte solution
}

Mitsuru Wakisaka ${ }^{\mathrm{a}, \mathrm{b},{ }^{*}}$ and Masashi Kunitake ${ }^{\mathrm{c}}$

${ }^{a}$ Fuel Cell Nanomaterials Center, University of Yamanashi, 6-43 Miyamae-cho, Kofu 400-0021, Japan.

b JST, PRESTO, 4-1-8 Honcho, Kawaguchi, Saitama, 332-0012, Japan.

${ }^{\mathrm{c}}$ Graduate School of Science and Technology, Kumamoto University, 2-39-1 Kurokami, Kumamoto, 860-8555, Japan.

* Corresponding author. Tel/fax: +81 552547094

E-mail address: wakisaka@yamanashi.ac.jp (M. Wakisaka)

\begin{abstract}
In the present study, we demonstrated a new concept for the direct electrochemical hydrogenation of toluene using an acidic microemulsion electrolyte with active Pt electrodes to pave the way for efficient methylcyclohexane mass production. We have achieved a Faradaic efficiency of $80 \%$ for the toluene/methylcyclohexane conversion at a Pt black electrode, under galvanostatic conditions and in a one-compartment cell. The reaction rate and selectivity of the toluene reduction were found to depend strongly on the surface structure of the Pt electrodes.
\end{abstract}

Keywords: organic hydride, hydrogenation, microemulsion, Pt electrode, surface-sensitive reaction, hydrogenolysis

\section{Introduction}

To build a hydrogen-based society, it is imperative to establish a large-scale hydrogen supply system. Organic chemical hydrides have been attracting considerable attention as hydrogen carriers, because they are liquid at ambient temperature and pressure [1]. Recently, the Chiyoda Corporation has demonstrated a large-scale hydrogen storage and transportation system making use of organic chemical hydride technology involving the catalytic hydrogenation of toluene, forming methylcyclohexane (MCH), and the dehydrogenation of $\mathrm{MCH}$ [2].

From the viewpoints of the effective use of electricity from renewable sources such as photovoltaics and wind-power, and the total energy conversion efficiency, the direct electrochemical hydrogenation of toluene is preferable to the conventional multistep reaction process consisting of water electrolysis and gas-solid catalytic toluene hydrogenation with the produced hydrogen. So far, 
there have been several studies of the direct electrochemical hydrogenation of toluene by employing a membrane electrode assembly (MEA) that consisted of a polymer electrolyte, Pt-based nanoparticle electrodes containing an ionomeric binder, and carbon paper [3-5]. However, it is questionable whether the MEA approach is best suited to the electrochemical hydrogenation of liquid aromatic organics, because MEAs have been developed for fuel cells and water electrolyzers in which the reactants or products are gaseous.

Toluene is an organic that has very low solubility in aqueous solution. The question arises-how can toluene be supplied to a catalyst in a facile manner in an aqueous solution to react with protons? One of the possible strategies is to use a microemulsion, which is a thermodynamically stable system that consists of organic and aqueous phases, plus surfactants. In a microemulsion, the electrochemical contact between the electrode and both micro-aqueous and organic phases can be simultaneously achieved by controlling the hydrophilicity and lipophilicity of the electrode surface [6-10]. So far, Rusling and co-workers have investigated the direct electrochemical reduction of arenes such as naphthalene and biphenyl at a non-catalyzed carbon electrode in neutral microemulsion media where the substrates were diluted with an organic solvent such as hexane $[11,12]$. However, these workers reported that only partial hydrogenation of aromatic rings and low Faraday efficiencies were achieved [11,12].

In the present study, we demonstrated the direct electrochemical hydrogenation of toluene using an acidic microemulsion electrolyte with active Pt electrodes. We achieved a Faradaic efficiency of $80 \%$ for the toluene/methylcyclohexane conversion at a Pt black electrode. Furthermore, we found that the reaction rate and selectivity of the toluene reduction depend strongly on the surface structure of the Pt electrodes.

\section{Material and Methods}

\subsection{Microemulsion}

The microemulsion electrolyte for the direct toluene hydrogenation was prepared from undiluted toluene (6 mL; 99.7\% Cica-reagent for spectroscopy, Kanto Chemical Co., Inc., Japan) with sodium 1-dodecanesulfonate $(0.75 \mathrm{~g}$; >98\% hygroscopic, Tokyo Chemical Industry Co., Ltd., Japan), t-butyl alcohol (1 mL; 99.0\% Cica-reagent, Kanto Chemical Co., Inc., Japan) and $6 \mathrm{~mL}$ of $1 \mathrm{M} \mathrm{H}_{2} \mathrm{SO}_{4}$ aqueous solution. The $1 \mathrm{M} \mathrm{H}_{2} \mathrm{SO}_{4}$ solution was prepared by diluting $96 \% \mathrm{H}_{2} \mathrm{SO}_{4}$ (Suprapur, Merck KGaA, Germany) with Milli-Q water. The chemical mixture was sonicated for $40 \mathrm{~min}$ and then left at least for a day to achieve equilibrium at room temperature. Figure 1a shows a photo of the prepared microemulsion electrolyte, which separated into three phases (Winsor III type), i.e., organic phase, surfactant-rich middle phase and aqueous $\left(1 \mathrm{M} \mathrm{H}_{2} \mathrm{SO}_{4}\right)$ phase. The surfactant-rich middle phase exhibited a blue color due to Rayleigh scattering. The average diameter of the micelles in the middle phase was estimated to be $11 \mathrm{~nm}$ via a small-angle X-ray scattering (SAXS, Nano-STAR, 
Bruker AXS) measurement.

\subsection{Cell Configuration}

Figure 1b shows a schematic diagram of the three-electrode, single-compartment cell filled with the microemulsion electrolyte for the direct electrochemical hydrogenation of toluene. The working electrode (WE) is placed in the middle phase, at which the toluene hydrogenation occurs via the following half-cell reaction:

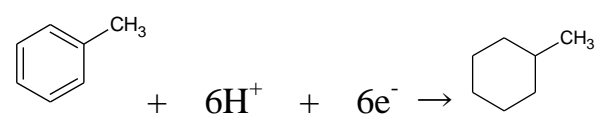

The produced $\mathrm{MCH}$ can be obtained from the organic phase, because the $\mathrm{MCH}$ molecules can diffuse through the middle phase. On the other hand, the counter electrode (CE) is placed in the aqueous phase, at which the oxygen evolution reaction takes place as follows:

$$
\mathrm{H}_{2} \mathrm{O} \rightarrow 1 / 2 \mathrm{O}_{2}+2 \mathrm{H}^{+}+2 \mathrm{e}^{-}
$$

Thus, protons can be continuously supplied from the aqueous phase to the middle phase. Consequently, the overall cell reaction can be expressed as follows:

$$
\overbrace{}^{\mathrm{CH}_{3}}+3 \mathrm{H}_{2} \mathrm{O} \rightarrow 3 / 2 \mathrm{O}_{2}
$$

On the basis of the standard reaction Gibbs free energy, the standard cell voltage $U^{0}$ for the overall reaction (3) can be calculated to be $1.07 \mathrm{~V}$. Thus, the standard electrode potential $E^{\mathrm{o}}$ for the half-cell reaction of (1) is $0.16 \mathrm{~V}$ vs. the standard hydrogen electrode (SHE) [3-5]. In the present study, a reversible hydrogen electrode (RHE) in aqueous $1 \mathrm{M} \mathrm{H}_{2} \mathrm{SO}_{4}$ was employed as the reference electrode. Hereinafter, all of the electrode potentials are reported vs. RHE

Unlike MEA-type cells, various forms of working electrodes can be examined in the microemulsion electrolysis cell. In the present study, we tested two types of Pt working electrodes, i.e. a mirror-finished Pt disk electrode ( $3 \mathrm{~mm}$ in diameter) purchased from ALS Co., Ltd., and a Pt-black grid electrode prepared by platinization of a 80 mesh/inch Pt grid $(0.5 \mathrm{~cm} \times 0.5 \mathrm{~cm}$; Nilaco Corporation, Japan) in a chloroplatinic acid solution at $10 \mathrm{~mA}$ for $5 \mathrm{~min}$. Prior to electrochemical measurements, each Pt working electrode was subjected to 10 potential cycles between 0.05 and $1.30 \mathrm{~V}$ in pure $1 \mathrm{M} \mathrm{H}_{2} \mathrm{SO}_{4}$ solution in order to clean the electrode surface. Electrochemically-active areas of the Pt electrodes were calculated from measured hydrogen adsorption charge densities on the basis of the theoretical value of $210 \mu \mathrm{Ccm}^{-2}$.

\section{Results and Discussion}

\subsection{Cyclic voltammetry and Chronoamperometry}

Figure 2a shows cyclic voltammograms (CVs) at a mirror-finished Pt disk electrode in $1 \mathrm{M} \mathrm{H}_{2} \mathrm{SO}_{4}$ solution, $1 \mathrm{M} \mathrm{H}_{2} \mathrm{SO}_{4}$ solution containing the surfactants (sodium 1-dodecanesulfonate and t-butyl 
alcohol), and the toluene microemulsion electrolyte. Each solution was deaerated with pure $\mathrm{N}_{2}(6 \mathrm{~N}$, Sumitomo Seika Chemicals Co., Ltd., Japan). The CV in the blank $\mathrm{H}_{2} \mathrm{SO}_{4}$ exhibited a characteristic reversible hydrogen adsorption wave below $0.4 \mathrm{~V}$ and an irreversible Pt surface oxidation wave above $0.7 \mathrm{~V}$. However, the characteristic hydrogen adsorption and surface oxidation waves were suppressed in the surfactant-containing $1 \mathrm{M} \mathrm{H}_{2} \mathrm{SO}_{4}$ solution, probably due to adsorption of the surfactants on the Pt electrode surface over the whole potential range.

In the toluene microemulsion electrolyte, the hydrogen adsorption and surface oxidation waves were also suppressed due to the adsorption of the surfactants in the same manner as in the surfactant-containing electrolyte. However, a large reduction current arose around $0.15 \mathrm{~V}$, i.e., quite positive compared to that for the hydrogen evolution reaction (HER). This large reduction current can be attributed to the toluene hydrogenation based on the standard potentials. Figure $2 \mathrm{~b}$ shows chronoamperograms (CAs) of the mirror-finished Pt electrode at $0.03 \mathrm{~V}$ after a potential step from $0.40 \mathrm{~V}$ in the same three solutions. The reduction currents in the blank and surfactant-containing $\mathrm{H}_{2} \mathrm{O}_{4}$ solutions dropped steeply, while that in the toluene microemulsion remained around $70 \mu \mathrm{A}$ $\mathrm{cm}^{-2}, 5$ times larger than the current for the HER.

\subsection{Faraday Efficiency and Selectivity}

We then carried out a potentiostatic electrolysis of toluene at $0.02 \mathrm{~V}$ by using the mirror-finished Pt electrode. The electrolysis was conducted in a single-compartment cell at room temperature without stirring the microemulsion solution. After the electrolysis, $1 \mu \mathrm{l}$ of the organic phase was sampled for a product analysis by gas chromatography (GC) using a GC-4000-plus (GL Sciences Inc., Japan) with a flame ionization detector. The Faradaic efficiency $\eta_{\mathrm{F}}$ of toluene/ $\mathrm{MCH}$ conversion was estimated via the following equation:

$$
\eta_{\mathrm{F}}=\mathrm{N}_{\mathrm{MCH}} \times 6 \mathrm{~F} / \mathrm{Q} \times 100
$$

where $\mathrm{N}_{\mathrm{MCH}}, \mathrm{F}$ and $\mathrm{Q}$ are the amount of synthesized $\mathrm{MCH}$ [mol] determined by the GC analysis, the Faraday constant $\left[\mathrm{C} \mathrm{mol}^{-1}\right]$, and consumed charge $[\mathrm{C}]$, respectively. Contrary to our expectation, the Faradaic efficiency of toluene/MCH conversion at the flat Pt electrode was only less than $20 \%$. However, we found cyclohexane as the predominant product in the GC analysis, in an amount twice that of $\mathrm{MCH}$. The formation of cyclohexane is presumably due to the further reduction of $\mathrm{MCH}$ (hydrogenolysis) yielding $\mathrm{CH}_{4}$, undetectable in the $\mathrm{GC}$ measurement, as expressed in the following reaction:

$$
\bigcup^{\mathrm{CH}_{3}}+2 \mathrm{H}^{+}+2 \mathrm{e}^{-} \rightarrow{ }_{+\mathrm{CH}_{4}}
$$

The standard electrode potential for the half-cell reaction of (5) can be calculated to be $0.23 \mathrm{~V}$ vs. SHE, more positive than that for the toluene hydrogenation. Thus, the formation of cyclohexane during the toluene hydrogenation was quite reasonable from the thermodynamic viewpoint. 
However, we found that the $\mathrm{MCH}$ hydrogenation was a structure-sensitive reaction on Pt electrode surfaces. We also performed a galvanostatic electrolysis of the toluene microemulsion at $1 \mathrm{~mA}$ using the Pt black grid electrode, which had a large electrochemically-active area, $90.5 \mathrm{~cm}^{2}$ (apparent roughness factor 360). Surprisingly, the Faraday efficiency of toluene/MCH conversion was much improved up to ca. $80 \%$ at the Pt black electrode. No significant product other than $\mathrm{MCH}$ was found in the GC analysis. Thus, $20 \%$ of the remaining charge in the electrolysis might be consumed mainly by the competitive HER, secondarily by reduction of oxygen generated at the counter electrode and/or reduction of surfactants (most likely t-butyl alcohol).

We then examined the reactivity of $\mathrm{MCH}$ at both the flat Pt electrode and the Pt-black electrode in a microemulsion containing MCH instead of toluene. Figure 3 shows steady-state polarization curves for the $\mathrm{MCH}$ microemulsion as well as the toluene microemulsion. It should be noted that the current densities were based on the electrochemically-active areas, not the geometric areas. It is clearly demonstrated in Figure 3 that both toluene hydrogenation and $\mathrm{MCH}$ hydrogenolysis are strongly surface-structure sensitive reactions. At the smooth Pt electrode (mirror-finished), the reaction rate of $\mathrm{MCH}$ was higher than that of toluene over the whole potential range. In contrast, the high area Pt black electrode exhibited the inverse, a reaction rate for $\mathrm{MCH}$ lower than that for toluene. In addition, it should be pointed out that the area-specific activities of the Pt black electrode towards both the toluene hydrogenation and the $\mathrm{MCH}$ hydrogenolysis were lower than those of the smooth Pt electrode. The present result that the flat Pt electrode rather than the high area Pt electrode promoted the $\mathrm{MCH}$ hydrogenolysis seemed against the conventional understanding in gas-solid catalytic reactions that $\mathrm{C}-\mathrm{C}$ bond scission is facilitated by kink sites on a Pt catalyst [13]. This opposite trend in reaction selectivity might originate from the unique reaction field at the microemulsion-electrode interface where the surfactants as well as (bi)sulphate anions strongly adsorb on the electrode surfaces (specifically, the high area Pt black) to block kink sites.

\section{Conclusion}

In the present study, we have demonstrated a new concept for the direct electrochemical hydrogenation of toluene at Pt electrodes in a microemulsion electrolyte solution. We have achieved a Faradaic efficiency of $80 \%$ for the toluene/MCH conversion at a Pt black electrode under galvanostatic conditions and in a one-compartment cell. The reaction rate and selectivity of the toluene reduction were found to depend strongly on the surface structure of the Pt electrodes. GC analyses revealed that $\mathrm{MCH}$ hydrogenolysis proceeded at a flat $\mathrm{Pt}$ electrode in $\mathrm{MCH}$-containing microemulsions. The present preliminary results indicate that our microemulsion approach, which is much simpler and cheaper than the MEA approach, has great potential for the direct electrochemical hydrogenation of aromatic organics as well as other hydrocarbon conversion reactions such as hydrogenolysis. However, further investigations on high activity, high selectivity electrocatalysts, 
inert surfactants, as well as cell designs, are required to achieve higher Faradaic efficiency and mass production of $\mathrm{MCH}$.

\section{Acknowledgement}

This research was supported by Japan Science and Technology Agency, PRESTO.

\section{References}

[1] E. Bewson, TH. Haueter, P. Hottinger, F. Von Roth, G. W. H. Scherer, TH. H. Schucan, Seasonal storage of hydrogen in stationary systems with liquid organic hydrides, Int. J. Hydrog. Energy 23 (1998) 905-909.

[2] Y. Okada, E. Sasaki, E. Watanabe, S. Hyodo, H. Nishijima, Development of dehydrogenation catalyst for hydrogen generation in organic chemical hydride method, Int. J. Hydrog. Energy 31 (2006) 1348-1356.

[3] P. Wang, T. Minegishi, G. Ma, K. Takanabe, Y. Satou, S. Maekawa, Y. Kobori, J. Kubota, K. Domen, Photoelectrochemical conversion of toluene to methylcyclohexane as an organic hydride by $\mathrm{Cu}_{2} \mathrm{ZnSnS}_{4}$-based photoelectrode assemblies, J. Am. Chem. Soc. 134 (2012) 2469-2472.

[4] V. Kalousek, P. Wang, T. Minegishi, T. Hisatomi, K. Nakagawa, S. Oshima, Y. Kobori, J. Kubota, K. Domen, Conversion of Toluene and Water to Methylcyclohexane and Oxygen using Niobium-Doped Strontium Titanate Photoelectrodes, ChemSusChem 7 (2014) 2690-2694.

[5] S. Mitsushima, Y. Takakuwa, K. Nagasawa, Y. Sawaguchi, Y. Kohno, K. Matsuzawa, Z. Awaludin, A. Kato, Y. Nishiki, Membrane Electrolysis of Toluene Hydrogenation with Water Decomposition for Energy Carrier Synthesis, Electrocatalysis 2015. DOI:10.1007/s12678-015-0289-3.

[6] R. A. Mackay and J. Texter, Electrochemistry in Colloids and Dispersions, Wiley-VCH, Weinheim, 1992.

[7] John Texter, Reactions and Synthesis in Surfactant Systems, Marcel Dekker, Inc., New York, 2001.

[8] J. F. Rusling, Electrochemistry in Micelles and Microemulsions, in: E. Calvo (Ed.), Encyclopedia of Electrochemistry, Vol. 2, Interfacial Kinetics and Mass Transport, Willey-VCH, Weinheim, 2003, pp. 418-439.

[9] S. Yoshitake, A. Ohira, M. Tominaga, T. Nishimi, M. Sakata, C. Hirayama, M. Kunitake, Electrochemistry in middle phase microemulsion composed of saline and toluene with sodium dodecylsulfate and n-butanol, Chem. Lett. 3(2002) 360-361.

[10] E. Kuray, S. Nagatomo, K. Sakata, D. Kato, O. Niwa, T. Nishimi, M. Kunitake, Simultaneous Electrochemical Analysis of Hydrophilic and Lipophilic Antioxidants in Bicontinuous Microemulsion, Anal. Chem. 87 (2015) 1489 -1493. 
[11] M. O. Iwunze, A. Sucheta and J. F. Rusling, Bicontinuous microemulsions as media for electrochemical studies, Anal. Chem. 62 (1990) 644-649.

[12] H. Carrero, J. Gao, J. F. Rusling, C.-W. Lee and A. J. Fry, Direct and catalyzed electrochemical syntheses in microemulsions, Electrochim. Acta 45 (1999) 503-512.

[13] G. A. Somorjai, Catalysis by Surfaces, in Introduction to Surface Chemistry and Catalysis, John Wiley \& Sons, New York, 1994, 442-595. 
Fig. 1 (a) Photo of the prepared toluene microemulsion. (b) Schematic diagram of the electrochemical cell for the direct electrochemical hydrogenation of toluene.

Fig. 2 (a) $\mathrm{CVs}$ and (b) $\mathrm{CAs}$ at a mirror-finished Pt electrode in $1 \mathrm{M} \mathrm{H}_{2} \mathrm{SO}_{4}$, surfactant-containing 1 $\mathrm{M} \mathrm{H}_{2} \mathrm{SO}_{4}$ and the toluene microemulsion electrolyte at room temperature, indicated by black, green and red lines, respectively.

Fig. 3 Steady-state polarization curves at the flat Pt electrode (squares) and the Pt black electrode (circles) in the toluene microemulsion (red symbols) and $\mathrm{MCH}$ microemulsion (blue ones) at room temperature. The electrode potentials were iR-corrected. 
Fig. 1

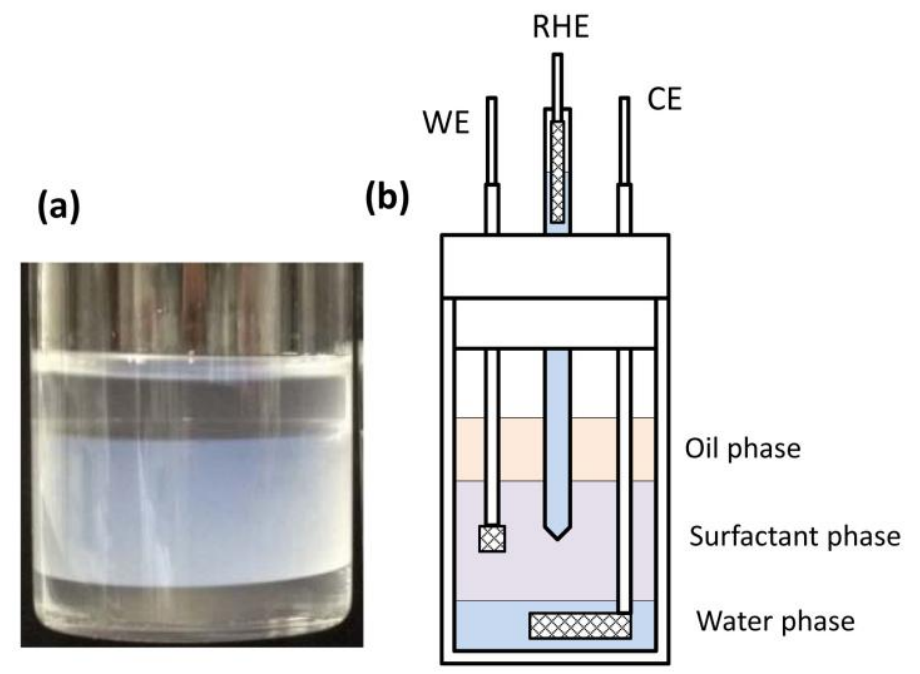


Fig. 2
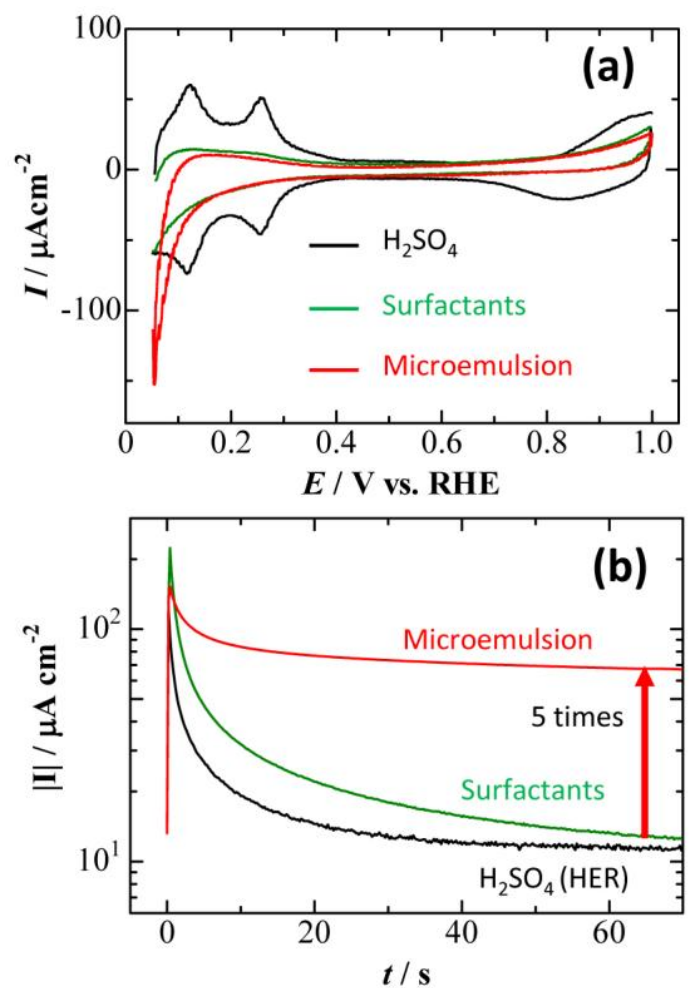
Fig. 3

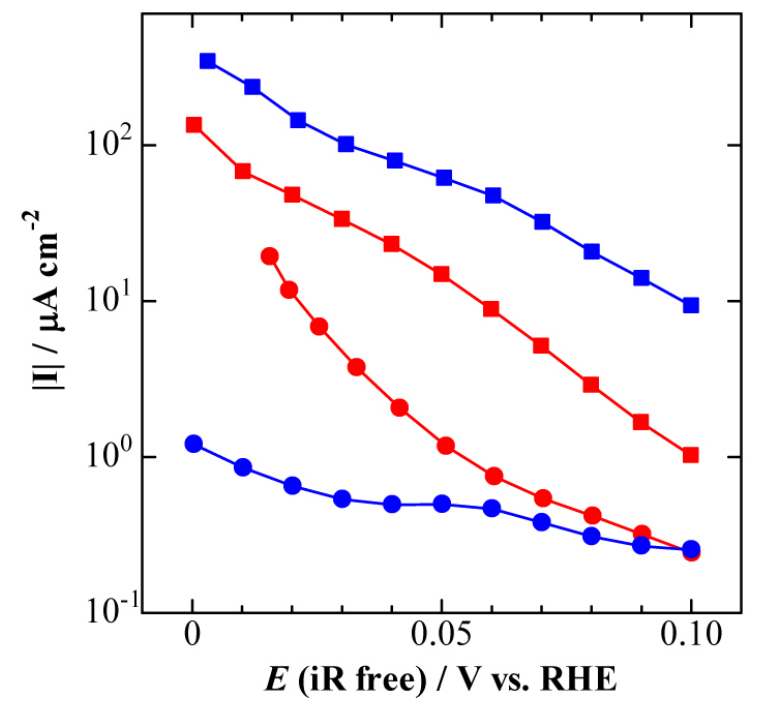



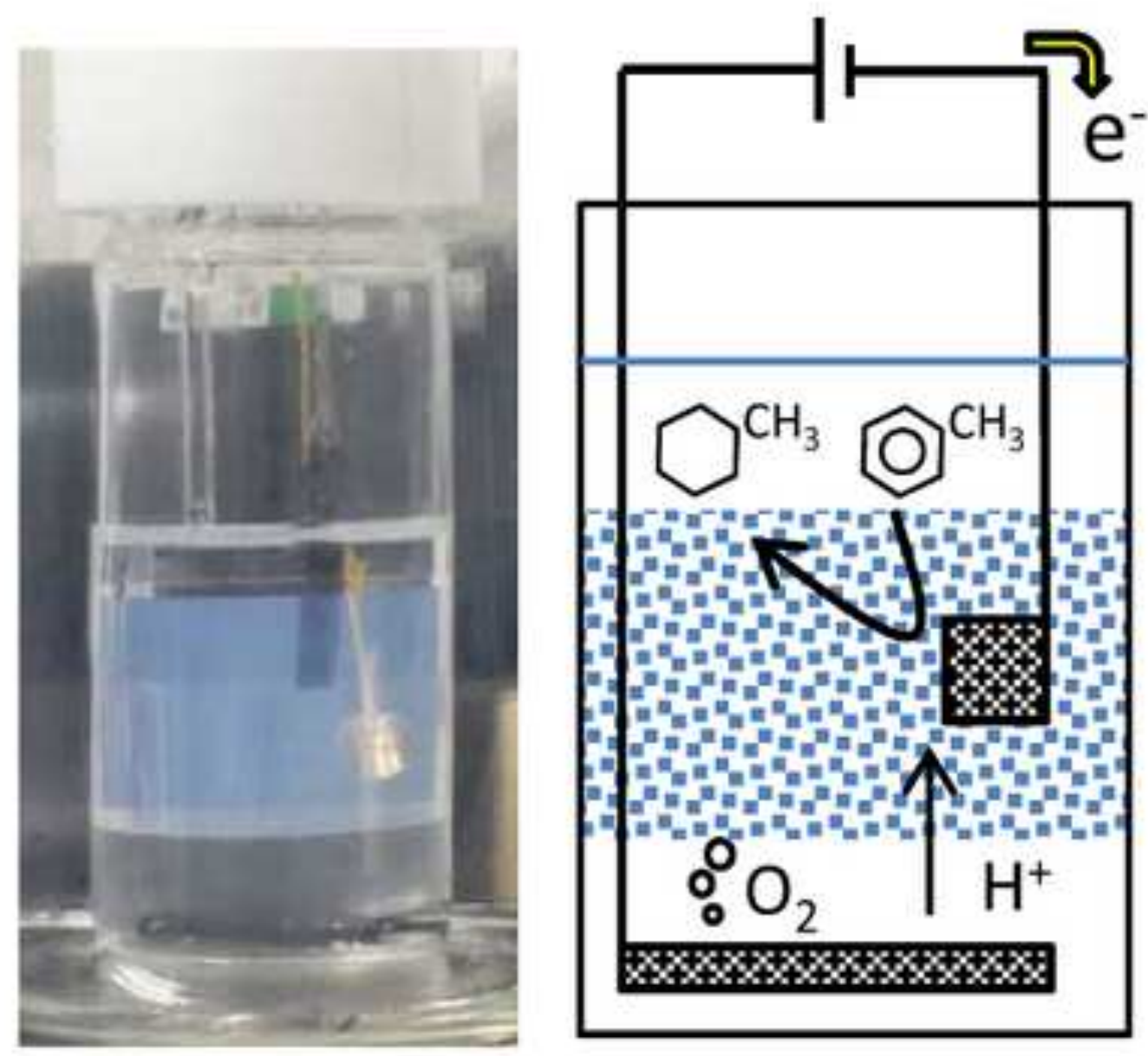

$\begin{array}{cc}\stackrel{\mathrm{O}}{\|} & \stackrel{\mathrm{OH}}{I} \\ \mathrm{CH}_{3}\left(\mathrm{CH}_{2}\right)_{11}-{ }_{\|}^{\mathrm{S}}-\mathrm{ONa} & \mathrm{CH}_{3}-\stackrel{\mathrm{C}}{\mathrm{C}}-\mathrm{CH}_{3} \\ \mathrm{O} & \stackrel{\mathrm{C}}{\mathrm{C} H_{3}}\end{array}$

Organic Phase

Surfactant-rich

Middle Phase:

$\widehat{0}^{\mathrm{CH}_{3}}+6 \mathrm{H}^{+}+6 \mathrm{e}^{-} \rightarrow \bigcirc^{\mathrm{CH}_{3}}$

Water Phase:

$\mathrm{H}_{2} \mathrm{O} \rightarrow 1 / 2 \mathrm{O}_{2}+2 \mathrm{H}^{+}+2 \mathrm{e}^{-}$ 